\title{
Murcha de fusário em helicônia: fontes de resistência, método alternativo de detecção e defesa estrutural
}

\author{
Neilza Reis Castro $^{1 *}$, Rildo Sartori Barbosa Coêlho², Delson Laranjeira' ${ }^{1}$, Rejane Magalhães de Mendonça Pimentel ${ }^{3}$, \\ Clébio Pereira Ferreira ${ }^{3}$
}

\begin{abstract}
${ }^{1}$ Departamento de Fitoss anidade, Universidade Federal Rural de Pernambuco, UFRPE, CEP 52171-900, Recife, PE; ${ }^{2}$ Empresa Pernambucana de Pesquisa Agropecuária, IPA. Sede, CEP 50761-000, Recife, PE; ${ }^{3}$ Departamento de Botânica, Universidade Federal Rural de Pernambuco, UFRPE, PE, CEP 52171-900, Recife, PE; *Parte da Tese de Doutorado do primeiro autor apresentada à Universidade Federal Rural de Pernambuco. Bolsis ta CNPq; Trabalho desenvolvido com apoio da Facepe/Promata

Autor para correspondência: Neilza Reis Castro (neilzacastro@ gmail.com)

Data de chegada: 02/04/2007. Aceito para publicação em: 10/02/2009.
\end{abstract}

1467

\section{RESUMO}

Castro, N.R.; Coêlho, R.S.B.; Laranjeira, D.; Pimentel, R.M. de M.; Ferreira, C.P. Murcha de fusário em helicônia: fontes de resistência, método alternativo de detecção e defesa es trutural. Summa Phytopathologica, v.36, n.1, p.30-34, 2010.

O cultivo das helicônias vem sendo afetado pela murcha, causada por Fusarium oxysporum f.sp. cubense. Este trabalho objetivou identificar fontes de resistência, verificar a detecção da resistência através de método alternativo e avaliar a lignificação como mecanismo de defesa do hospedeiro ao patógeno. As espécies utilizadas na identificação de resistência foram Heliconia bihai, H. psittacorum cvs. Golden Torch e Golden Torch Adrian, H. rostrata, H. stricta cvs. Capri e Fire Bird, H. psittacorum cvs. Sassy e Alan Carle, H. caribea, $H$. latispatha, $H$. wagneriana e $H$. chartacea cv. Sexy Pink. A avaliação dos sintomas foi realizada aos 40 dias após a inoculação baseada em escala de notas variando de 1 a 6 . As espécies consideradas resistentes foram H. bihai, $H$. psittacorum cvs. Golden Torch e Golden
Torch Adrian, H. rostrata, H. stricta cv. Capri, H. psittacorum cv. Sassy e H. caribea. O método alternativo de detecção de resistência consistiu na utilização de filtrado fúngico obtido a partir do cultivo em meio Czapek, utilizando várias concentrações do mesmo depositando em folhas destacadas das cultivares resistentes e suscetíveis $H$. psittacorum cvs. Golden Torch e Alan Carle, respectivamente. A avaliação foi feita após 48 horas de incubação, onde a concentração em $50 \%$ do filtrado foi a mais eficiente na distinção da resistência. O mecanismo estrutural foi observado em secções histológicas nas raízes das espécies utilizadas no estudo de resistência, inoculadas com o método de injeção e não inoculadas, que permitiram verificar a ausência de relação entre a resistência e a lignificação.

Pala vras-chave adicionais: Fusa rium oxysporum, espécies resistentes, filtrado fúngico, lignific ação

\section{ABSTRACT}

Castro, N.R.; Coêlho, R.S.B.; Laranjeira, D.; Pimentel, R.M. de M.; Ferreira, C.P. Heliconia's Fusarium wilt: resistance sources, alternative method of detection and structural mechanisms. Summa Phytopathologica, v.36, n.1, p.30-34, 2010.

Heliconia grown as a crop has been affected by wilt, caused by Fusarium oxysporum f.sp. cubense. This work aimed to identify genetic resistances sources, to evaluated the detection of resistance with an alternative method and to verify the effects of structural mechanisms in pathogen resistance. The genotypes evaluated were Heliconia bihai, H. psittacorum cv. Golden Torch, H. psittacorum cv. Golden Torch Adrian, H. rostrata, H. stricta Capri, H. psittacorum cv. Sassy, H. caribea, H. latispatha, H. wagneriana, $H$. psittacorum cv. Alan Carle, $H$. stricta cv. Fire Bird and $H$. chartacea cv. Sexy Pink. These genotypes were inoculated with a F. oxysporum f.sp. cubense isolate and the symptoms were evaluated 40 days after inoculation, based on an disease rating scale ranging from 1 to 6 . The genotypes considered resistant were H. bihai, H. psittacorum cvs. Golden Torch and Golden Torch Adrian, H. rostrata, H. stricta cv. Capri, H. psittacorum cv. Sassy and $H$. caribea. The alternative method for resistance detection consisted in the utilization of fungal filtrades obtained after cultivation in Czapek medium. Several concentrations of filtrates were evaluated on detached of $H$. psittacorum cvs. Golden Torch (resistant) and Alan Carle (susceptible) cultivars. The evaluation was carried out at 48 hours of incubation, and the filtrate with concentration of $50 \%$ was the more efficient for distinction of resistance. Structural resistance mechanism was analyzed in histological sections in roots of the species inoculated and non inoculated utilized in resistance study. It was possible to verify the absence of relation of resistance in the lignification of root cells.

Keywords: Fusarium oxysporum, resistant species, fungic filtrate, lignification

A utilização da resistência genética na redução de perdas ocasionadas pordoenças vem sendo ampliada, principalmente para as doenças onde o controle químico é ineficiente (1). Esta alternativa de controle também é incentivada pela consciência ecológica e pela cons cientização das consequiências causadas por uso inadequado de agrotóxicos. A murcha de fusário, causada pelo Fusarium oxysporum f.sp cubense (E.F. Smith) Snyd. \& Hans., fungo habitante do solo, de difícil controle, vem causando prejuízos ao setor da floricultura tropical, 
inclusive ao cultivo das helicônias (Heliconia spp.).

O uso de espécies resistentes e a identificação de fontes promissoras de resistência para o emprego em programas de melhoramento vegetal tornam-se a medida mais eficiente e econômica no controle da murcha de fusário (2). O sucesso do melhoramento de plantas requer técnicas eficientes levando-se em consideração as possíveis fontes de resistência, o conhecimento dos caracteres genéticos e fisioló gicos envolvidos no processo e estratégias apropriadas (6).

Várias técnicas vêm sendo exploradas para a seleção de fontes de resistência. As avaliações de plantas em campo e em casa de vegetação ainda são as mais usadas, mas consistem em técnicas que requerem longos períodos de tempo e os resultados podem ser influenciados por fatores ambientais e biológicos como temperatura, umidade, presença de pragas e/ou outros fitopatógenos (6). Ultimamente, novas técnicas vêm surgindo e permitindo resultados mais rápidos e menos destrutíveis como os experimentos conduzidos em laboratório utilizando-se partes destacadas de plantas, como o uso de extratos fúngicos em folhas, caules e rizomas. Pesquisas têm revelado sucesso no emprego destas técnicas em relação a alguns patos sistemas $(2,4,6$, 11, 17). Os filtrados fúngicos contêm toxinas produzidas pelos fitopatógenos que afetam as plantas alterando a permeabilidade da membrana celular, inativando a ação enzimátic a, levando as células do tecido do hospedeiro ao colapso (1).

Em relação à defesa de plantas ao ataque de patógenos, ocorrem mecanismos que contribuem para a resistência no hospedeiro, dentre esses mecanismos, destacam-se os estruturais que atuam como barreiras físicas, evitando ou restringindo o avanço do fitopatógeno e, como conseqüência, o desenvolvimento da doença (10). Os mecanismos estruturais, como os bioquímicos, podem ser pré-formados e pós formados. As cutículas, tricomas, estômatos, fibras, papilas, halos, lignificação, camada de cortiça e tiloses fazem parte deste arsenal de defesa no hosped eiro (1).

A lignina consiste em uma das substâncias mais importantes da parede celular, presente na lamela média, paredes primária e secundária, composta por unidades de fenilpropano e seu acúmulo é ativado enzimaticamente através da peroxidase (16). A lignificação já foi constatada como mecanismo de defesa em alguns trabalhos referentes à resistência genética, muitos deles estão relacionados ao gênero Fusarium $(14,15)$, inclusive na interação $F$. oxysporum f.sp cubense vs. bananeira, onde se constatou uma maior produção de lignina na cultivar resistente utilizada no experimento (5).

Em razão do pouco conhecimento sobre o patossistema $F$. oxysporum f.sp cubense vs. Heliconia spp., o presente trabalho objetivou a identificação de possíveis fontes de resistência à murcha de fusário, verificar a eficiência do uso de filtrados fúngicos na distinção de espécies resistentes e suscetíveis e verificar a influência da lignificação, como mecanismo es trutural de defesa ao patógeno.

\section{MATERIALE MÉTODOS}

\section{Caracterização de espécies de Heliconia spp. como fontes de resistência}

Os experimentos foram conduzidos em casa de vegetação, sendo realizadas inoculações em plantas de diversas espécies de helicônia. As espécies inoculadas foram Heliconia wagneriana Peters, $H$. chartacea Lom. cv. Sexy Pink, $H$. caribaea Lam. cv. Yellow Sun, $H$. bihai L., H. latispatha Benth., H. rostrata Ruiz \& Pavan, H. stricta
Huber cvs. Capri e Fire Bird, H. psittacorum L. cvs. Sassy, Alan Carle, Golden Torch e Golden Torch Adrian. As inoculações foram feitas por injeção de $2 \mathrm{~mL}$ de suspensão fúngica (concentração de $10^{6}$ conídios.mL$\left.{ }^{1}\right)$ no colo das plantas com 90 dias de idade. Foi utilizado o isolado F17 de F. oxysporum f.sp. cubense oriundo do município de Marechal Deodoro-AL. As avaliações foram feitas aos 40 dias após a inoculação através de escala de nota variando de 1 a 6 , onde 1 = plantas sadias, sem sintomas externos ou internos observáveis no caule cortado na altura do primeiro internódio logo acima dos cotilédones; 2 = vasos coloridos na região do primeiro internódio sem outros sintomas visíveis; 3 = vasos coloridos até a altura da primeira folha, com pelo menos um folíolo com amarelecimento; 4 = vasos coloridos até a metade do comprimento do caule, com 2 ou mais folhas com amarelecimento $; 5=$ vasos coloridos até próximo ao ponteiro, maioria das folhas murchas, com exceção do ponteiro; e 6 = plantas mortas, ou com vasos coloridos e folhas murchas até o ponteiro (18). O delineamento experimental foi inteiramente casualizado com 12 repetições e os dados analisados através do teste de Scott-Knot $(\mathrm{p}=0,05)$ no programa SAEG 9.0.

Efeito do filtrado fúngico em folhas destacadas de espécies de Helicônia

O experimento foi conduzido em condições de laboratório. Foi utilizado o isolado F17 de F. oxysporum f.sp. cubense, cultivado por sete dias em meio BDA (batata dextrose ágar). Discos de micélio contendo estruturas do fungo foram transferidos para Erlenmeyers de $250 \mathrm{~mL}$ contendo $100 \mathrm{~mL}$ de meio Czapek. O fungo foi incubado no meio por 24 dias sob alternância luminosa e em temperatura ambiente. As colônias fúngicas foram agitadas manualmente duas vezes por dia. Ao final do cultivo, as colônias foram filtradas em papel de filtro esterilizado e o volume obtido foi concentrado de $400 \mathrm{~mL}$ para $80 \mathrm{~mL}$ em evaporador à vácuo. $\mathrm{O}$ volume líquido obtido após a evaporação foi utilizado sem diluir (concentração 100\%) e diluído para 75, 50 e $25 \%$ de concentração. Folhas destacadas das H. psittacorum cv. Alan Carle e Golden Torch foram utilizadas como padrões de suscetibilidade e resistência, respectivamente. A inoculação deu-se através da deposição de $1 \mathrm{~mL}$ de cada filtrado na superfície das folhas previamente lavadas e secadas. Antes da deposição do líquido, foram realizadas perfurações em pequenos círculos com auxílio de agulha hipodérmica. As folhas inoculadas foram incubadas por quatro dias, em alternância luminosa e sob condição de câmara úmida. Após o período de incubação, foi observada a formação de lesões no local da inoculação do filtrado.

\section{Avaliação da lignificação envolvida no patossistema}

A coleta das raízes para a avaliação da lignificação foi realizada aos 40 dias após a inoculação por injeção no colo da planta. Os tratamentos foram: inoculado com o isolado F17 de F. oxysporum f.sp. cubense e não inoculado (testemunha). As raízes coletadas foram fixadas em FAA 95\% (50 mL de etanol a 95\%, $5 \mathrm{~mL}$ de ácido acético, $10 \mathrm{~mL}$ de formol e $35 \mathrm{~mL}$ de água destilada). Em seguida, todo o material foi conduzido ao laboratório e tratado seguindo a metodologia de Johansen (8). As secções histológicas foram coradas com safranina, azul de astra e floroglucina para identificação da lignina, segundo Krauter (9).

Imagens digitais das secções histológicas, dos diferentes órgãos vegetativos da espécie em estudo, foram produzidas sob microscopia óptica (Olympus) com câmera digital (Sony) acoplada. As escalas e numerações foram inseridas utilizando se imagens de lâmina micrométric a, obtidas sob condições idênticas àquelas utilizadas para a confecção das imagens das secções histológicas e programa Photoshop, versão 7.0 (Adobe Systems). 


\section{RESULTADOS E DISCUSSÃO}

As espécies utilizadas na identificação de fontes de resistência formaram quatro grupos caracterizados como resistente, medianamente resistente, suscetível e altamente suscetível (Tabela 1) baseando-se na escala de notas de Tokeshi \& Galli (18) e analisado estatisticamente pelo teste de Scott-Knot $(\mathrm{p}=0,05)$. Os dados obtidos pela avaliação dos sintomas internos e externos apresentaram alta correlação $(\mathrm{r}=$ $0,89)$ quando analisados através da correlação de Pearson.

Tabela 1. Se veridade da doença, causada por Fusarium oxysporum f.sp. cubense, em diferentes espécies de Heliconia, e classificação quanto à resistência ao fungo.

\begin{tabular}{lcc}
\hline Espécie & $\begin{array}{c}\text { Grau de } \\
\text { infecção }\end{array}$ & $\begin{array}{c}\text { Classificação de } \\
\text { resistência }\end{array}$ \\
\hline Heliconia stricta cv. Fire Bird & $6,0 \mathrm{a}$ & $\mathrm{AS}$ \\
H. chartacea cv. Sexy Pink & $4,0 \mathrm{~b}$ & $\mathrm{~S}$ \\
H. psittacorum cv. Alan Carle & $3,6 \mathrm{~b}$ & $\mathrm{~S}$ \\
H. wagneriana & $2,0 \mathrm{c}$ & $\mathrm{MR}$ \\
H. latispatha & $1,6 \mathrm{c}$ & $\mathrm{MR}$ \\
H. psittacorum cv. Sassy & $1,0 \mathrm{~d}$ & $\mathrm{R}$ \\
H. stricta cv. Capri & $1,0 \mathrm{~d}$ & $\mathrm{R}$ \\
H. rostrata & $1,0 \mathrm{~d}$ & $\mathrm{R}$ \\
H. caribea & $1,0 \mathrm{~d}$ & $\mathrm{R}$ \\
H. psittacorum cv. Golden Torch & $1,0 \mathrm{~d}$ & $\mathrm{R}$ \\
H. psittacorum $\mathrm{cv}$. Golden Torch Adrian $1,0 \mathrm{~d}$ & $\mathrm{R}$ \\
H. bihai & $1,0 \mathrm{~d}$ & $\mathrm{R}$ \\
\hline
\end{tabular}

CV $(\%)=11,08$. Médias seguidas da mesma letra na vertical não diferem entre si pelo teste de Tukey ao nível de $5 \%$ de probabilidade.

$\mathrm{R}=$ resistente, $\mathrm{MR}=$ moderadamente resistente, $\mathrm{S}=$ suscetívele $\mathrm{AS}=$ altamente suscetível.

As espécies consideradas resistentes foram: $H$. bihai, $H$. psittacorum cv. Golden Torch e Golden Torch Adrian, H. rostrata, $H$. stricta cv. Capri, H. psittacorum cv. Sassy e H. caribe, as espécies moderadamente resistentes foram H.latispatha e H. wagneriana. Heliconia psittacorum cv. Alan Carle e H. chartacea cv. Sexy Pink foram identificadas como suscetíveis. A única espécie do estudo que foi considerada como altamente suscetível foi a $H$. stricta $\mathrm{cv}$. Fire Bird. A H. bihai apresentou um comportamento diferenciado das demais espécies consideradas resistentes, exibindo leve descoloração vascular sem, no entanto, apresentar nenhum sintoma externo.

Das espécies estudadas, apenas $H$. caribea e H. latispatha já haviam sido avaliadas anteriormente por Waite (19) e apresentaram comportamento variado em relação a três isolados obtidos de diferentes espécies de helicônias. Heliconia caribea foi suscetível a um isolado e resistente aos demais e $H$. latispatha exibiu reação de resistência a todos os isolados, concordando com os resultados obtidos neste trabalho. Os resultados referentes à espécie $H$. caribea comprovam a variabilidade patogênicados isolados. Isto também pode ser observado em experimento de fontes de resistência na cultura da bananeira onde as reações apresentadas pelas cultivares do grupo FHIA variaram de resistente a moderadamente resistente, de acordo com o grupo de compatibilidade vegetativa (VCG) do qual os isolados de F. oxysporum f.sp. cubense pertenciam (13).

A concentração do filtrado fúngico em $50 \%$ foi a que indicou maior eficiência na distinção das espécies resistente e suscetível. Após 48 horas de incubação das folhas inoculadas, foi observada a formação de lesões apenas na cultivar Alan Carle, considerada padrão de suscetibilidade, ao contrário da cultivar Golden Torch que não apresentou lesões (Figura 1). Estas reações distintas também foram observadas em experimentos conduzidos por Companioni et al. (4) em inoculações de filtrado de $F$. oxysporum f.sp cubense em folhas de bananeira dos padrões de resistência e suscetibilidade, onde somente na cultivar suscetível “Gros Michel” formaram-se lesões. Es te método utilizando filtrado fúngico em partes destacadas do hospedeiro pode ser uma alternativa na identificação de fontes de resistência, apresentando como vantagens a rapidez dos resultados, a não destruição de plantas inteiras e o uso reduzido de espaço físico, uma vez que pode ser conduzido em laboratório. Resultados semelhantes também foram obtidos por Silva et al. (17), os quais conseguiram a distinção de suscetibilidade, suscetibilidade moderada e resistência nas cultivares de bananeira 'Maçã', 'Nanicão' e 'PrataAnã', em relação a um isolado de F.oxysporum f.sp. cubense, utilizando a técnica do rizoma inoculado e incubado sob condição de câmara úmida. Outra téc nica semelhante e efic iente foi a utilizad a por Matsumo to et al. (12), os quais cultivaram, in vitro, plântulas de bananeira em meio com ácido fusárico e observaram a distinção das reações de resistência e suscetibilidade.

Considerando que a avaliação da qualidade funcional da raiz está relacionada ao conteúdo de lignina nas células da endoderme (7), as espécies em estudo diferiram quanto à presença e ausência do espessamento em "U" e o grau de lignificação deste espessamento.

De modo geral, as espécies variaram quanto ao grau de espessamento e presença/ausência de lignificação nas células da endoderme nas diferentes espécies estudadas (Tabela 2). Esta variação
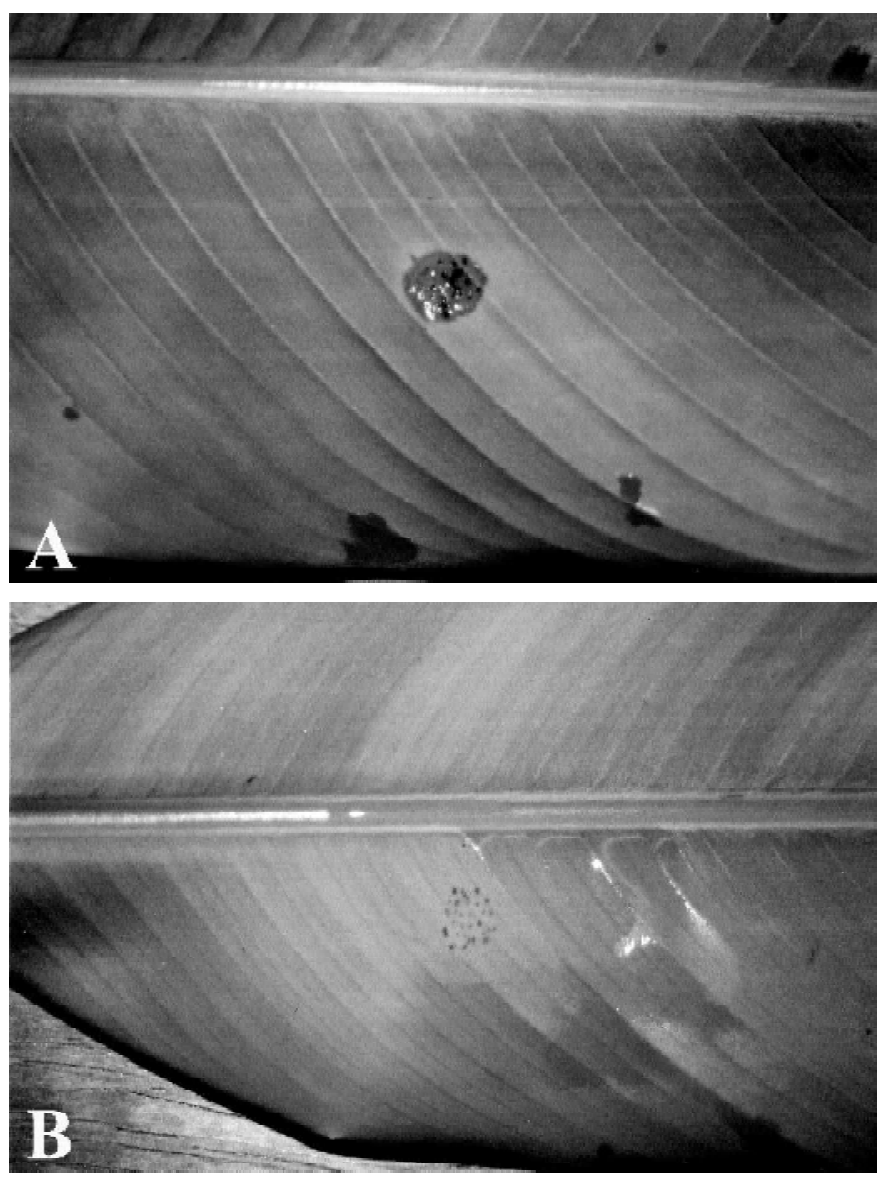

Figura 1. Formação de lesão (A) em Heliconia psittacorum cv. Alan Carle, suscetível a Fusarium oxysporum f.sp. cubense, e a ausência de lesão (B) em H. psittacorum cv. Golden Torch, resistente ao patógeno. 
de grau de espess amento pode ter ocorrido devido ao tipo de método de inoculação utilizado, aliado a não determinação da profundidade de inoculação. Três espécies, $H$. caribaea, $H$. psittacorum Golden Torch Adrian e $H$. wagneriana não apresentaram espessamento nem lignificação nos dois tratamentos testados. Três espécies, $H$. stricta cv. Capri, H. chartacea cv. Sexy Pink e H. psittacorum cv. Sassy, não apresentaram espessamento em "U”, nem lignificação no material inoculado. Entretanto, o material controle apresentou este espessamento com lignificação e variados valores de espessura (Tabela 2). Quatro espécies, H. bihai, H. psittacorum cv. Golden Torch, $H$. latispatha e $H$. rostrata, mostraram variação quanto ao grau de espessamento em "U” e intensidade de lignificação (Tabela 2).

Tabela 2. Valores médios do espessamento (ìm) em "U" e presença/ausência da endoderme radicular e lignificação, em espécies de Heliconia inoculada e não inoculadas com Fusarium oxysporum f.sp. cubense.

\begin{tabular}{lcc}
\hline Espécies & $\begin{array}{c}\text { Inoculada } \\
(\boldsymbol{\mu} \mathbf{m})\end{array}$ & $\begin{array}{c}\text { Não inoculada } \\
(\boldsymbol{\mu m})\end{array}$ \\
\hline Heliconia bihai & 2,24 & 2,27 \\
H. caribaea & E (-) L (-) & E (-) L (-) \\
H. chartacea & E (-) L (-) & 2,02 \\
H. latispatha & 3,19 & 1,80 \\
H. psittacorum Golden Torch & 3,0 & 5,80 \\
H. psittacorum Golden Torch Adrian & E (-) L (-) & E (-) L (-) \\
H. psittacorum Sassy & E (-) L (-) & 3,89 \\
H. rostrata & 1,80 & 2,83 \\
H. stricta cv. capri & E (-) L (-) & 3,56 \\
H. wagneriana & E (-) L (-) & E (-) L (-) \\
\hline
\end{tabular}

E (-) indica a ausência de endoderme radicular e L (-) indica a ausência de lignina

Os resultados obtidos mostram previamente que as espécies testadas do gênero Heliconia respondem de modo particular à ação do patógeno e que o tipo de inoculação utilizado também pode ter contribuído neste comportamento. A maior quantid ade de deposição de lignina na end oderme, determinada pela intensidade de coloração, foi observada nas espécies $H$. psittacorum cv. Golden Torch e $H$. latispatha. H. bihai, apesar de não ter mostrado alteração no grau de espessamento no material inoculado e controle, mostrou redução na quantidade de lignina (Figura 2). H. psittacorum cv. Golden Torch e $H$. rostrata reduziram o espessamento quase pela metade, enquanto $H$. latispatha mostrou comportamento contrário, isto é, aumentou o espessamento em quase o dobro (Tabela 2). Estes resultados mostram previamente que a espessura da parede celular e a lignificação podem não estar envolvidas na resistência ao $F$. oxysporum f.sp. cubense, uma vez que algumas espécies resistentes apresentaram o mesmo comportamento que a espécie suscetível, podendo-se sugerir a possibilidade da influência da metodologia de inoculação utilizada e da atuação de outros mecanis mos no processo da resistência. Resultados semelhantes foram constatados por Rodrigues (15) que observou a não detecção do aumento de lignina na parede celular, mesmo após a utilização de indutores de resistência, em cultivares resistente e suscetível de caupi (Vigna unguiculata L. (Walp) na interação com Fusarium oxysporum f.sp. tracheiphilum (E.F.Smith) Snyder \& Hansen. O acúmulo de lignina pode estar relacionado ao período após contato com o patógeno. Por exemplo, De Ascensão \& Dubery (5) puderam verificar o aumento no acúmulo de lignina em resposta a infecção de $F$. oxysporum f.sp. cubense nas raízes da cultivar de bananeira "Goldfinger", considerada resistente, entre quatro a 16 horas após a elicitação com o patógeno. Após este período observou-se um ligeiro decréscimo da lignina, enquanto que na cultivar "Williams" o acréscimo de lignina começou apenas de 12 a 16 horas após a interação.
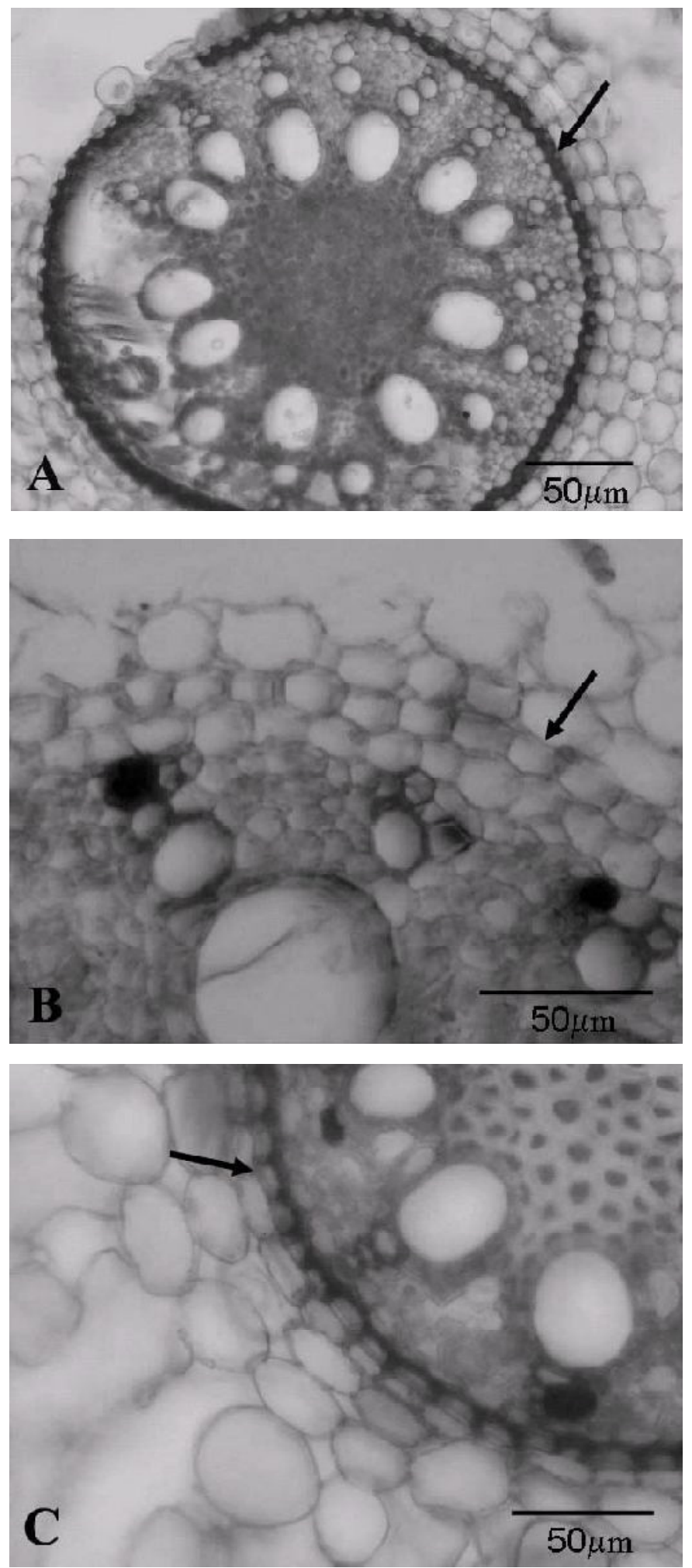

Figura 2. Secção transversal das raízes de Heliconia psittacorum Golden Torch (A), H. bihai (B) e H. latispatha (C) todas inoculadas, mostrando variado grau de lignificação no espessamento em "U" na endoderme. 


\section{REFERÊNCIAS BIBLIOGRÁFICAS}

1. Agrios, G.N. Plant Pathology. 5. ed. Amsterdan: Elsevier; Academic Press, 2005. 922p.

2. Castro, N.R.; Serra, I.M.R.S.; Coêlho, R.S.B.; Laranjeira, D. Patogenicidade de isolados de Fusarium oxysporum f.sp. cubense em Heliconia spp. Fitopatologia Brasileira, v.20, p.S140, 2006. (Resumo).

3. Companioni, B.; Arbola, M.; Rodrigues, Y.; Mosqueada, M.; Pérez, M.C. Borrás, O.; Lorenzo, J.C.; Santos, R. Use of culturederived Fusarium oxysporum f.sp. cubense, race 1 filtrates for rapid and non destructive in vitro differentiation between resistant and susceptible clones of field-grown banana. Euphytica Wageningen, v.130, p.341-347, 2003.

4. De Ascensão, A.R.D.C.F.; Dubery, I.A. Panama disease: cell wall reinforcement in banana roots in response to elicitors from $F u$ sarium oxysporum f.sp. cubense race four. Biochemistry and Cell Biology, Saint Paul, v.90, p.1173-1180, 2000.

5. Foolad, M.R.; Ntahimpera, N.; Christ, B.J.; Lin, G.Y. Comparison of field, greenhouse, and detached-leaflet evaluations of tomato germ plas $m$ for early blight resistance. Plant Disease, Saint Paul, v.84, p.967-972, 2000.

6. Gaspar, T.; Coumans, M. Root formation. In: Bonga, J.M.; Durtzan, D.J. (Eds.). Cell and tissues culture in forestry. Dordrecht: Springer, v.2, p.202-217, 1987.

7. Johasen, D.A. Plant microtecnique. New York. Mcteaw-Hill, 1940. 134p.

8. Krauter, D. Erfanhrungen mit Etzolds FSA-Farbung fur pflanzenschnitte. Mikroskosmos, New Mexico, v.74, p.231-233, 1997.

9. Leite, B.; Pascholati, S.F. Hospedeiro: alterações fisiológicas induzidas por fitopatógenos. In: Kimati, H.; Amorim, L.; Rezende, J.A.M.; Bergamin Filho, A.; Camargo, L.E.A (Ed.). Manual de fitopatologia, 1995, v.1, p.417-453.

10. Marchi, C.E.; Borges, M.F.; Mizubuti, E.S.G. Atividades amilolítica de Alternaria solani e a relação com a agressividade em toma- teiro. Summa Phytopathologica, Botucatu, v.32, p.345-352, 2006

11. Matsumoto, K.; Barbosa, M.L.; Souza, L.A.C.; Teixeira, J.B. Race 1 fusarium wilt tolerance on banana plants selected by fusaric acid. Euphytica, Wageningen, v.84, p.104-112, 1995.

12. Pérez-Vicente, L. Fusarium wilt (Panama disease) of bananas: an updating review of the current knowledge on the disease and its causal agent. In: Reunion International Acorbat 16., 2004, México. Anais, Oaxaca: Editora Acorbat, 2004. p.1-15.

13. Redman, R.S.; Freeman, S.; Clifton, D.R.; Morrel, J.; Brow, G.; Rodrigues, R.J. Biochemical analysis of plant protection afforded by a nonpathogenic endophytic mutant of Colletotrichum magna. Plant Physiology, Bethesda, v.119, p.795-804, 1999.

14. Rodrigues, A.A.C. Resistência de caupi a Fusarium oxysporum f.sp. tracheiphilum: avaliação de germoplasmas, indução de defesa e caracteri zação de mecanismos bi oquí mi cos, estruturais a análise da capacidade funcional do xilema. 2003. 134f. Tese (Doutorado em Fitopatologia) - Universidade Federal Rural de Pernambuco, Recife.

15. Shi, J.; Mueller, W.C.; Beckman, C.H. Ultrastructural responses of vessel contact cells in cotton plants resistant or susceptible to infection by Fusarium oxysporum f.sp. vasinfectum. Physiological and Molecular Plant Pathology, London, v.38, p.211222, 1991 .

16. Silva, R.D.C.; Mendes, M.A.S.; Tenente, R.C.V. Testes de virulência de Fusarium oxysporum f.sp. cubense em rizomas de bananeira. Fitopatologia Brasilei ra, Brasília, v.16, p.S199, 2002. (Resumo).

17. Tokeshi, H.; Galli, F. Variabilidade de Fusarium oxysporum f.sp. lycopersici (Wr.)Sny. \& Hans. em São Paulo. Anais da Escola Superior de Agricultura Luiz de Queiroz, Piracicaba, v.23, p.195-209, 1966.

18. Waite, B.H. Wilt of Heliconia spp. caused by Fusarium oxysporum f.sp. cubense race 3. Tropical Agriculture, Trinidade, v.40, p.299-305, 1963 